\title{
Discussões Sociocientíficas sobre o Uso de Agrotóxicos: uma Atividade Formativa Problematizada pelo Princípio da Precaução
}

\section{Socioscientific Discussions about the Use of Pesticides: a Activity for Teacher Training Problematized by the Precautionary Principle}

\author{
Leila Cristina Aoyama Barbosa Souza \\ Carlos Alberto Marques \\ Brasil \\ Brasil
}

O artigo apresenta análises sobre um processo de problematização desenvolvido em atividade formativa com professores de um curso Técnico em Agropecuária de instituição mato-grossense sobre o tema "uso de agrotóxicos nas atividades agrícolas". $\mathrm{O}$ planejamento e desenvolvimento dessa atividade, elaborada em perspectiva educacional freireana, pautaram-se em reflexões do tema "agrotóxicos" à luz do Princípio da Precaução e das interações Ciência, Tecnologia, Sociedade (CTS). Fazendo uso da Análise Textual Discursiva e das categorias epistemológicas freireanas de problematização e conscientização no tratamento analítico, evidenciaram-se lacunas e desestabilização dos conhecimentos prévios dos professores participantes para responder a questão problematizadora. Tal processo e a apreensão de novos conhecimentos durante a atividade formativa indicou a ampliação da visão de mundo dos professores e a tomada de consciência sobre o uso de agrotóxicos como um problema socioambiental.

Palavras-chave: abordagem CTS; perspectiva educacional freireana; educação profissional.

This work presents an analysis of a process of problematization developed in a training activity with teachers of a Technical Course in Agriculture of a Mato Grosso state institution about the topic "use of pesticides in agricultural activities". The planning and development of this activity, elaborated according to the educational perspective of Paulo Freire, were based on reflections on the theme "pesticides" in the light of both the Precautionary Principle and interactions between Science, Technology and Society (STS). The use of Discursive Textual Analysis and Paulo Freire's epistemological categories of problematization and awareness in analytic treatment showed gaps and destabilization of previous knowledge of the participating teachers when answering problematizing issues. This process and the learning of new knowledge during the activity indicated the expansion of worldview and the awareness of the use of pesticides as an environmental problem. 
Keywords: STS approach; Freire's educational perspective; professional education.

\section{Introdução}

O Brasil se destaca mundialmente pela sua grande produção agrícola, mas também como um dos maiores consumidores de agrotóxicos ${ }^{1}$ (Abrasco, 2010). Em 2014, mais de 508 mil toneladas de ingredientes ativos foram comercializadas no país (Ibama, 2015). As explicações que se replicam para justificar tal fato são: as grandes áreas de produção, a busca pela alta produtividade e a elevada adoção de sementes transgênicas - que exigem produtos químicos específicos para seu desenvolvimento (Miranda, Moreira, Carvalho, \& Peres, 2007).

A grandiosidade desses números despertou nosso interesse em investigar sobre o modo como a referida temática encontra-se inserida no ensino para a formação de técnicos agrícolas e por uma maneira de abordá-la promovendo a formação da consciência crítica dos sujeitos (Freire, 2005). Tal formação trata-se de um dos objetivos da educação para cidadania vislumbrada como educação para tomada de decisão (Auler, 2011; Santos, \& Schnetzler, 2010), isto é, quando os sujeitos são alfabetizados cientificamente e sentem-se aptos e estimulados a participar do processo de tomada de decisão sobre os rumos do desenvolvimento técnico-científico.

Praia, Gil-Pérez e Vilches (2007) afirmam que a participação democrática na tomada de decisões garante a aplicação do Princípio da Precaução (PP) em situações nas quais se desconhecem as consequências das inovações tecnocientíficas a médio e longo prazo; uma vez que tal princípio define que se existe uma ameaça, na qual há incertezas, alguma ação é obrigatória (Sandin, 1999). Logo, para que o princípio possa ser invocado pela sociedade, torna-se necessário sua apresentação e discussão na educação científica e tecnológica.

No entanto, apesar de estudos internacionais apontarem o PP como um elemento a ser considerado nas argumentações para a tomada de decisão em discussões sociocientíficas (Fensham, 2014; Kolsto, 2006), observamos, por meio de revisão em periódicos da área de ensino de ciências, que as publicações educacionais que esclarecem sobre tal inserção são escassas - principalmente na literatura brasileira (Souza, Marques, \& Machado, 2016). Desse modo, desenvolveu-se, em pesquisa de doutorado, uma investigação sobre as contribuições do PP para a promoção da alfabetização científica, tendo a formação do técnico agrícola como objeto de estudo (Souza, 2016).

Este artigo busca responder a questão de pesquisa: Como o Princípio da Precaução em discussões sociocientíficas sobre problemas ambientais do contexto agrícola mato-grossense pode contribuir para o enfrentamento da racionalidade instrumental na formação do técnico agrícola? Para tanto caracterizamos uma atividade formativa

1 Segundo o Decreto lei n. ${ }^{\circ} 4.074$ (2002), agrotóxicos são produtos e agentes de processos físicos, químicos ou biológicos, destinados a prevenir, destruir ou repelir, direta ou indiretamente, qualquer forma de agente patogênico ou de vida animal ou vegetal, que seja nociva às plantas e animais úteis, bem como as substâncias e produtos empregados como desfolhantes, dessecantes, estimuladores e inibidores de crescimento. 
desenvolvida com professores de um curso Técnico em Agropecuária de uma instituição mato-grossense ${ }^{2}$, cuja elaboração pautou-se em elementos do PP para discutir sobre o elevado uso de agrotóxicos no Brasil e as consequências disto ao ambiente e saúde. Além disso, analisamos o processo de problematização desenvolvido na atividade e o comportamento dos participantes diante dela, relatando as possíveis nuances da tomada de consciência dos sujeitos para desvelar a realidade. Com vistas a este fim, a atividade formativa foi elaborada de acordo com a perspectiva educacional freireana e a metodologia dos três momentos pedagógicos (Delizoicov, Angotti, \& Pernambuco, 2002). A perspectiva freireana ainda embasou o tratamento analítico dos dados coletados visto que preocupamo-nos em identificar, por meio da Análise Textual Discursiva (ATD) (Moraes, \& Galiazzi, 2006), elementos que sinalizassem a desestabilização das percepções iniciais dos professores e um olhar crítico para os impactos ao ambiente e seres vivos quanto ao uso de agrotóxicos nas atividades agrícolas - o que diz respeito às categorias de problematização e conscientização, respectivamente.

Assim, além de contribuir com as pesquisas da área de educação profissional, o trabalho torna-se relevante ao ensino de ciências ao abordar elementos constituintes do PP na promoção de discussões sociocientíficas e apontar aspectos a serem considerados na avaliação do êxito de atividades didáticas em perspectiva freireana no seu tratamento analítico.

\section{O Princípio da Precaução e sua articulação com aspectos Ciência, Tecnologia, Sociedade (CTS) no ensino de ciências}

O PP surgiu legalmente nos anos de 1970 em países nórdicos, sob o termo Vorsorgeprinzip, para tratar das regulamentações que protegiam o meio ambiente em caso de situações de incertezas e riscos quanto à ação de algum produto ou processo (Lieber, 2008). Presente em diversas legislações ambientais, como a Declaração sobre Meio Ambiente e Desenvolvimento (ONU, 1992) e o regulamento europeu de controle à produção de substâncias químicas - o Registration, Evaluation and Authorisation of Chemicals (REACH) (Comissão das Comunidades Europeias, 2001), não há uma formulação única desse princípio. Porém, de modo geral, todas as formulações esclarecem a adoção de medidas em casos de atividades que ocasionem possíveis danos ao ambiente e à vida.

Em essência, o Princípio da Precaução provê um argumento para uma tomada de ação contra uma atividade ou uma substância quando houver ausência de uma certeza científica em vez da continuação de uma prática suspeita enquanto ela está sob pesquisa ou mesmo ainda sem avaliação.

2 A escolha de uma instituição mato-grossense e de professores formadores de técnicos agrícolas para a realização da atividade formativa desta pesquisa deve-se ao campo de atuação profissional da primeira autora deste artigo. 
Em vez de perguntar qual o nível de dano é aceitável, a precaução questiona: quanto de contaminação pode ser evitada? Quais são as alternativas para o produto ou atividade em questão? Elas são seguras? A atividade é realmente necessária? (Tickner, \& Raffensperger, 1998, p. 03, tradução nossa).

A utilização do PP para avaliar uma situação científica que apresente ameaças, permite uma reflexão sobre as incertezas científicas e, consequentemente, sobre os limites do uso dos conhecimentos científicos e tecnológicos em processos que envolvam impactos ambientais. Frequentemente, tais incertezas relacionam-se à divergência de resultados de pesquisas sobre a segurança e impactos de um produto ou processo, a exemplo, os impactos do cultivo de organismos geneticamente modificados (transgênicos) ao ambiente e de seu consumo para a saúde, a influência das atividades antrópicas no quadro global de mudanças climáticas e o potencial cancerígeno à saúde pela constante exposição a campos eletromagnéticos de linhas de energia.

A discussão de casos, como os exemplificados acima, em ambiente educacional, além dos conteúdos científicos envolvidos, possibilita avaliar e romper o pensamento ingênuo sobre o desenvolvimento da ciência e tecnologia (C\&T) em um modelo linear de progresso que sempre culmina no bem-estar social. Para tanto, é preciso compreender os elementos que realimentam tal modelo: o determinismo tecnológico (concepção do desenvolvimento da $C \& T$ como processo irreversível e sem relevância da ação humana), a perspectiva salvacionista de C\&T (crença na capacidade da C\&T resolver automaticamente todos os problemas) e a tecnocracia (tomada de decisões por especialistas) (Auler, \& Delizoicov, 2006).

Pensar sobre as incertezas científicas também possibilita a tomada de consciência sobre a não neutralidade da ciência e os interesses que existem por demandas específicas de pesquisa. Em relação a isso, Delizoicov e Auler (2011) explicam que, por vezes, demandas importantes de um determinado espaço-tempo não são selecionadas para a formulação de problemas científicos que contribuiriam para atendê-las, devido, em certa perspectiva de valor a não serem consideradas pertinentes à agenda de pesquisa adotada. Como exemplos dessa situação, citamos: 1) o contraste entre o alto investimento em pesquisas biotecnológicas para resolver problemas do agronegócio e o escasso financiamento e estímulo às pesquisas agroecológicas (Lacey, 2007); e 2) a cooperação internacional para o combate da epidemia de Ebola na África, em 2014, apenas quando surgiu o risco da doença se tornar pandêmica (Lopes, \& Dunda, 2015).

Especificamente sobre o uso de agrotóxicos nas atividades agrícolas brasileiras, tema selecionado para nossa investigação, o PP contribui nas discussões sociocientíficas sobre ingredientes ativos que apresentam incertezas científicas quanto às probabilidades de impactos negativos ao ambiente e saúde, como o glifosato. Segundo informações do Centro Nacional Americano de Informação sobre Pesticidas (NPIC, 2014), esse ingrediente ativo apresenta baixo nível de toxicidade crônica e potencial negativo tanto para a carcinogenicidade (capacidade de provocar o surgimento de tumores malignos) como para a genotoxicidade (capacidade de induzir alterações no material genético 
de um organismo). Por isso, no Brasil, a Agência Nacional de Vigilância Sanitária (ANVISA) classifica-o como produto pouco perigoso (classe IV). No entanto, existem estudos experimentais e clínicos que evidenciam resultados inversos a esses, indicando o potencial genotóxico, alergênico, interferente endócrino (Belo, Pignati, Dores, Moreira, \& Peres, 2012) e até mesmo cancerígeno ${ }^{3}$ da substância (Guyton et al., 2015).

Um resultado definitivo sobre os danos provenientes da utilização do glifosato parece não se restringir às questões de procedimentos metodológicos das pesquisas, mas perpassar por questões políticas e econômicas ao localizarmos tal ingrediente ativo como constituinte de herbicidas amplamente utilizados em plantações transgênicas e os elevados números envolvidos nessa cadeia produtiva. No Brasil, em torno de $90 \%$ das áreas plantadas de soja, milho e algodão são transgênicas (Céleres, 2015) e, no ano de 2014, o faturamento da indústria de agrotóxicos superou os U\$ 12 bilhões (ABRASCO, 2015), sendo que $43 \%$ do consumo desses produtos referem-se ao glifosato (IBAMA, 2015). Assim, a tecnologia que previa a redução na quantidade de agrotóxicos aplicados nas lavouras (tanto em variedade como em volume) torna o modelo agrícola brasileiro altamente dependente de apenas um tipo deles, de maneira a prejudicar toda a produção nacional de grãos caso o produto seja banido devido a efeitos tóxicos à saúde ou ambiente.

Outro aspecto elucidado pela discussão sociocientífica do tema agrotóxicos, problematizado pelo PP, relaciona-se à explicitação do modelo de sociedade de risco que tem sido adotado. Observa-se que a utilização, por parte do Estado, de um paradigma do uso seguro de agrotóxicos demonstra crença na mensuração dos riscos a que estamos expostos, bem como no total controle deles. Isso se exemplifica pela quantificação de valores limites que não provocariam prejuízo à saúde ou ambiente, como a IDA (Ingestão Diária Aceitável) e o NOAEL (Nível de Efeito Adverso Não-Observado), sua utilização em legislações pertinentes, bem como pelos manuais contendo regras do correto transporte, armazenamento e aplicação de produtos químicos.

Rigotto (2011) questiona se não é uma ilusão acreditar que seja possível existir um uso seguro de agrotóxicos, visto que há uma gama de fatores envolvidos nesse processo, como: o nível de escolaridade dos trabalhadores que manipulam tais produtos, a quantidade de agrotóxicos utilizados e o elevado número de estabelecimentos agropecuários instalados, as políticas públicas existentes, a falta de fiscalização pelas instituições públicas, entre outros. Na mesma direção, ao discutir sobre a poluição química global, Thornton (2000) aponta seis falhas sobre a crença em limites aceitáveis de exposição de produtos químicos que parecem ser pouco percebidos: 1) ignora-se processos biológicos, como a bioacumulação, ao se acreditar na capacidade assimilativa dos ecossistemas em absorver e degradar poluentes; 2) desconsidera-se a dispersão global da poluição química e a simultaneidade e continuidade de milhares de outras fontes poluidoras; 3 ) desconsidera-se os efeitos sinérgicos que aumentam a toxidez e complexidade das misturas dos diversos produtos químicos no ambiente; 4) há poucas

3 Em 2015, a Agência Internacional para a Pesquisa sobre o Câncer (IARC, na sigla em inglês) apontaram estudos de casos-controle da exposição ocupacional nos Estados Unidos, Canadá e Suécia demonstrando aumento na taxa de câncer em indivíduos expostos - particularmente do linfoma não-Hodgkin (Guyton et al., 2015). 
pesquisas científicas sobre os danos oriundos de moléculas químicas; 5) pouco se tem observado que rotas sintéticas controladas geram produtos indesejáveis e muitos outros ainda desconhecidos; e 6) não se percebe a ineficácia das tecnologias de controle e descarte de produtos químicos, que só mudam o tempo, a forma e o local da exposição.

Para o enfrentamento desse modelo atual pautado no risco e em suas medidas quantificáveis, Thornton (2000) propõe que o PP seja considerado a fim de prover um olhar mais cauteloso que se antecipe na previsão de danos ambientais. Lacey (2006) também defende o uso do PP para enfrentar distorções correntes das práticas científicas que as subordinam a valores comerciais e políticos - como os interesses econômicos envolvidos na utilização dos agrotóxicos no Brasil, aqui citados anteriormente.

Desse modo, acreditamos que o PP apresenta potencial para ser inserido em discussões sobre problemas ambientais e para ser utilizado em ambiente educacional, contribuindo à promoção da alfabetização científica crítica que associa a aprendizagem de conteúdos científicos à discussão das relações CTS e, a partir disso, busque a formação de sujeitos que compreendam e questionem a realidade em que se encontram. No caso de nossa investigação, objetivou-se a ampliação da percepção dos sujeitos sobre as consequências socioambientais e os interesses políticos e econômicos envolvidos no elevado uso de agrotóxicos nas atividades agrícolas brasileiras, bem como o papel das atividades científicas no processo de regulamentação desses produtos químicos. Tais percepções se devem a leitura de mundo que os sujeitos apresentam. Sobre isto, acreditamos que a perspectiva de educação defendida por Paulo Freire, pautado na dialogicidade e conscientização, podem contribuir ao alcance do pensamento crítico dos sujeitos para compreender a realidade e as situações de opressão existentes. A seguir, comentamos alguns aspectos da perspectiva freireana que justificam tal afirmativa.

\section{A perspectiva educacional freireana como promotora da leitura crítica de mundo}

Paulo Freire (2005) ao pensar em educação, concebe-a como um processo realizado pelos seres humanos e para os seres humanos, isto é, a educação em comunhão onde estes são "mediatizados pelo mundo" (p. 79). Para o educador pernambucano, o processo educacional deve estar diretamente relacionado

à vivência dos sujeitos, seus contextos, seus problemas, suas angústias e, acima de tudo, às contradições presentes no "mundo vivido". [...]

Freire propôs uma educação que estimulasse a colaboração, a decisão, a participação, a responsabilidade social e política e, acima de tudo, a constituição de um sujeito autônomo (Gehlen, Auth, Auler, Maldaaner, \& Pansera-de-Araújo, 2008, p. 286).

A educação em perspectiva freireana busca a ação transformadora que vai além da aprendizagem de conceitos e conteúdos. É um processo educativo pautado em perguntas problematizadoras que questionam a realidade, o papel da sociedade, a causa e consequências de fatos. Conforme aponta a professora Ana Maria Saul em entrevista 
(Magalhães, 2007), não basta que nossos estudantes, por exemplo, compreendam o que é água, seus diferentes estados físicos ou sua fórmula química. É importante que, juntamente com tais conceitos científicos, eles entendam o que significa ter (ou não) água para a sobrevivência e dignidade humana, por que o acesso à água tratada não é um bem comum a todos ou por que se tem alagamentos quando chove.

Nesta perspectiva, a educação torna-se dialógica ao promover o compartilhamento de experiências entre educadores e educandos ao invés da simples transmissão de conteúdos dos primeiros atores para os segundos, processo denominado educação bancária. Ao buscar a interdisciplinaridade das diversas áreas do conhecimento, como, por exemplo, das ciências e matemáticas com a sociologia e geografia - uma vez que a realidade não é fragmentada em áreas - a educação torna-se um ato político (Freire, 1979; 2005). Desse modo, auxilia os sujeitos, a partir de um processo de conscientização, a compreender seu papel na realidade, as situações opressoras existentes e a necessidade por agir em prol da mudança.

Nossa proposta de atividade formativa a professores formadores de técnicos agrícolas encontrou apoio nos fundamentos da educação problematizadora de Paulo Freire justamente pela situação-limite que identificamos, no decorrer de nossa investigação (Souza, 2016), quanto ao elevado uso de agrotóxicos nas atividades agrícolas e à forte dependência existente a estes produtos químicos.

Freire (2008) explica que situações-limites dizem respeito a situações condicionantes da liberdade humana, que se manifestam nos obstáculos e barreiras da vida social e pessoal de homens e mulheres que precisam ser vencidas. O pensamento de senso comum difundido no país é o que diz ser impossível a produção agrícola em larga escala sem o uso de agrotóxicos. Sendo assim, parece que as atividades agrícolas tornamse reféns de tal prática baseada em insumos químicos - proporcionando a manutenção do status quo. Entretanto, convém ressaltar que o PP vem justamente nos alertar sobre a necessidade de repensarmos as atividades humanas passíveis de situações de risco e incerteza tanto ao ambiente como à própria saúde humana.

Acreditamos que a problematização de tal princípio em discussões de temáticas do ensino de ciências que envolvam situações de risco e/ou incertezas científicas podem contribuir para o desvelamento e compreensão da realidade. Este processo de conscientização ocorre a partir do reconhecimento das influências sociopolíticas e econômicas envolvidas na realidade, em um movimento de educação política e crítica - conforme defendido pela perspectiva educacional freireana. Com isto, em busca de compreender sobre modos de discutir e problematizar o PP no ensino, na seção que segue, descrevemos as etapas da atividade formativa proposta a professores de um curso Técnico em Agropecuária, bem como os demais procedimentos metodológicos adotados. 


\section{Caracterização da atividade realizada e do grupo participante}

A partir delevantamentobibliográfico sobre os impactos toxicológicos e ambientais de alguns tipos de agrotóxicos e reflexões sobre as incertezas científicas envolvidas no uso desses produtos, foi elaborada uma atividade formativa a professores formadores de técnicos agrícolas. $\mathrm{O}$ intuito foi discutir a temática dos agrotóxicos em perspectiva sociocientífica, isto é, tratando sobre aspectos da relação CTS e das incertezas científicas que acarretam na diversidade de decisões plausíveis para o problema, e enfatizando, ainda, os aspectos políticos e econômicos envolvidos nas atuais decisões das políticas públicas brasileiras sobre o assunto.

Assim, as características da situação pedagógica objeto desta investigação e os objetivos da atividade formativa construída justificam a adoção de procedimentos metodológicos e analíticos na perspectiva educacional freireana. Nesse sentido, pedagogicamente, a atividade foi estruturada pelos três momentospedagógicos (Delizoicov, Angotti, \& Pernambuco, 2002): 1) Problematização inicial - etapa de diagnóstico na qual são apresentadas algumas situações reais e os sujeitos são motivados a opinar de maneira a adquirir um distanciamento crítico; 2) Organização do conhecimento - em que novos conhecimentos são apresentados aos sujeitos a fim de compreender sobre o tema explorado e a problematização iniciada na etapa anterior; 3) Aplicação do conhecimento - que se destina a verificar como os conhecimentos apresentados na etapa anterior podem ser utilizados para interpretar as situações iniciais propostas pelo estudo, bem como outras que podem ser compreendidas pelo mesmo conhecimento. A Figura 1 traz informações sobre cada etapa da atividade. Com carga horária de 16 horas, foram propostos cinco encontros presenciais com duração de 2 horas cada e outros quatro momentos não presenciais de 1:30 hora, utilizados para leituras de textos que estimulassem a discussão do próximo encontro.

$\mathrm{Na}$ etapa de Problematização inicial, buscamos compreender as percepções iniciais dos professores sobre a temática agrotóxicos no contexto local. Para tanto, partiu-se de uma narrativa sobre a contaminação ambiental de um município matogrossense devido à pulverização aérea de agrotóxicos em uma lavoura próxima a área urbana. A segunda etapa (Organização do conhecimento) objetivou a apresentação de conteúdos científicos relacionados ao tema, como os indicadores toxicológicos e de periculosidade ambiental dos principais ingredientes ativos de agrotóxicos consumidos em Mato Grosso e os possíveis destinos finais dessas substâncias químicas nos diversos compartimentos ambientais (hidrosfera, litosfera e atmosfera). Essa etapa compreendeu ainda a problematização do PP para discutir sobre a natureza da ciência e os interesses e valores envolvidos nas incertezas científicas sobre os impactos ambientais do uso de agrotóxicos. Por fim, a etapa de Aplicação do conhecimento tratou-se do momento em que os professores puderam refletir sobre a necessidade e viabilidade da aplicação do PP ao julgar novamente o caso discutido na etapa inicial da atividade. 


\begin{tabular}{|c|c|c|c|}
\hline Etapa & $\begin{array}{l}\text { Objetivo da ativi dade } \\
\text { formativa }\end{array}$ & Encontros elaborados & $\begin{array}{l}\text { Carga } \\
\text { horária }\end{array}$ \\
\hline \multirow{3}{*}{$\begin{array}{l}\text { Problematização } \\
\text { inicial }\end{array}$} & \multirow{3}{*}{$\begin{array}{l}\text { Apresentar o caso do acidente } \\
\text { rural de Lucas do Rio } \\
\text { Verde/MT a fim de coletar } \\
\text { julgamentos e procedimentos } \\
\text { adotados pelos professores } \\
\text { diante do acidente químico } \\
\text { ocorrido em Lucas do Rio } \\
\text { Verde. }\end{array}$} & $\begin{array}{l}\text { Encontro 1: O acidente rural de } \\
\text { Lucas do Rio Verde: origem, causas e } \\
\text { consequências. }\end{array}$ & $2 \mathrm{~h}$ \\
\hline & & $\begin{array}{l}\text { Pré-encontro 2: Leitura de Kugler, } \\
\text { H. (2012). Paraíso dos agrotóxicos. } \\
\text { Ciência Hoje, } 50 \text { (296), 20-25. }\end{array}$ & $1: 30 \mathrm{~h}$ \\
\hline & & $\begin{array}{l}\text { Encontro 2: O uso de agrotóxicos em } \\
\text { MT e a dependência do monocultivo. }\end{array}$ & $2 \mathrm{~h}$ \\
\hline \multirow[t]{2}{*}{$\begin{array}{l}\text { Organização do } \\
\text { conhecimento }\end{array}$} & \multirow[t]{2}{*}{$\begin{array}{l}\text { Problematizar sobre o uso } \\
\text { de agrotóxicos, por meio de } \\
\text { indicadores toxicológicos } \\
\text { e ambientais de alguns } \\
\text { ingredientes ativos e } \\
\text { definições de abordagens de } \\
\text { risco. }\end{array}$} & $\begin{array}{l}\text { Pré-encontro 3: Leitura de Belo, } \\
\text { M. S. S. P. et al. (2012). Uso de } \\
\text { agrotóxicos na produção de soja do } \\
\text { estado do Mato Grosso: um estudo } \\
\text { preliminar de riscos ocupacionais e } \\
\text { ambientais. Revista Brasileira de Saúde } \\
\text { Ocupacional, } 37 \text { (125), 78-88. }\end{array}$ & $1: 30 \mathrm{~h}$ \\
\hline & & $\begin{array}{l}\text { Encontro 3: Os riscos potenciais } \\
\text { envolvidos no uso de agrotóxicos. }\end{array}$ & $2 \mathrm{~h}$ \\
\hline \multirow[t]{2}{*}{$\begin{array}{l}\text { Organização do } \\
\text { conhecimento }\end{array}$} & \multirow[t]{2}{*}{$\begin{array}{l}\text { Apresentar o princípio da } \\
\text { precaução como elemento } \\
\text { científico para discutir } \\
\text { questões ambientais na } \\
\text { formação do técnico } \\
\text { agrícola. }\end{array}$} & $\begin{array}{l}\text { Pré-encontro 4: Leitura de Rigotto, } \\
\text { R. (2011). O uso de agrotóxicos } \\
\text { é possível? In: F. Londres (Org.) } \\
\text { Agrotóxicos no Brasil: um guia para } \\
\text { ação em defesa da vida (pp. 48-51). } \\
\text { Rio de Janeiro: AS-PTA - Assessoria } \\
\text { e Serviços a Projetos em Agricultura } \\
\text { Alternativa. }\end{array}$ & $1: 30 \mathrm{~h}$ \\
\hline & & $\begin{array}{l}\text { Encontro 4: A contribuição do } \\
\text { princípio da precaução para novos } \\
\text { olhares sobre riscos ambientais. }\end{array}$ & $2 \mathrm{hs}$ \\
\hline \multirow[t]{2}{*}{$\begin{array}{l}\text { Aplicação do } \\
\text { conhecimento }\end{array}$} & \multirow{2}{*}{$\begin{array}{l}\text { Analisar como os professores } \\
\text { propõem a utilização do } \\
\text { PP para analisar o caso do } \\
\text { acidente rural de Lucas do } \\
\text { Rio Verde/MT, bem como } \\
\text { seus posicionamentos sobre } \\
\text { a aplicabilidade de inserção } \\
\text { do Princípio da Precaução } \\
\text { no ensino para formação do } \\
\text { técnico agrícola. }\end{array}$} & $\begin{array}{l}\text { Pré-encontro 5: Leitura de Souza, L. } \\
\text { C. A. B., Marques, C. A., \& Machado, } \\
\text { A. A. S. C. (2015). Como discutir o } \\
\text { Princípio da Precaução no Ensino de } \\
\text { Ciências? } 8 \text { p. Acervo dos autores (não } \\
\text { publicado). }\end{array}$ & $1: 30 \mathrm{~h}$ \\
\hline & & $\begin{array}{l}\text { Encontro 5: Inserção do princípio da } \\
\text { precaução no ensino para formação } \\
\text { de técnicos agrícolas. }\end{array}$ & $2 \mathrm{hs}$ \\
\hline \multicolumn{3}{|c|}{ Carga horária total } & $16 \mathrm{hs}$ \\
\hline
\end{tabular}

Figura 1. Caracterização da atividade formativa, elaborada com base nos Três Momentos Pedagógicos

Fonte: Dos autores. 
A atividade formativa foi realizada em junho de 2015 com um grupo de seis professores de um curso Técnico em Agropecuária de instituição pública matogrossense. Tratou-se de um grupo jovem de professores (faixa etária de 20 a 40 anos), de distribuição igualitária de gênero (três homens e três mulheres) que, em sua maioria, possuíam até cinco anos de experiência docente na educação profissional ou em outras modalidades de ensino. Em relação à formação profissional, três são agrônomos, um biólogo, um médico veterinário e um zootecnista. Seus níveis de titulação variavam da graduação ao doutorado em andamento.

Todos os encontros da atividade formativa foram gravados em áudio e as falas foram transcritas, codificadas de acordo com os sujeitos (P-1 a P-6) e analisadas segundo procedimentos da ATD. A técnica caracteriza-se como um processo auto-organizado de construção, do qual emergem novas compreensões e entendimentos sobre o fenômeno investigado a partir das etapas de unitarização, categorização e comunicação (Moraes, \& Galiazzi, 2006). Além de se tratar, notoriamente, de uma ferramenta analítica de dados em estudos da área do ensino de ciências (Gonçalves, \& Marques, 2006; Oliveira, \& Recena, 2009; Prestes, Lima, \& Ramos, 2011), há estudos que evidenciam aproximações das etapas metodológicas da ATD com a abordagem freireana de Investigação temática (Torres et al., 2008).

\section{Análise da atividade formativa na perspectiva da educação problematizadora}

A Figura 2 elenca as subcategorias que emergiram do processo analítico da ATD, cujas categorias principais fundamentaram-se nos conceitos freireanos de problematização e conscientização (Freire, 1983; 2005).

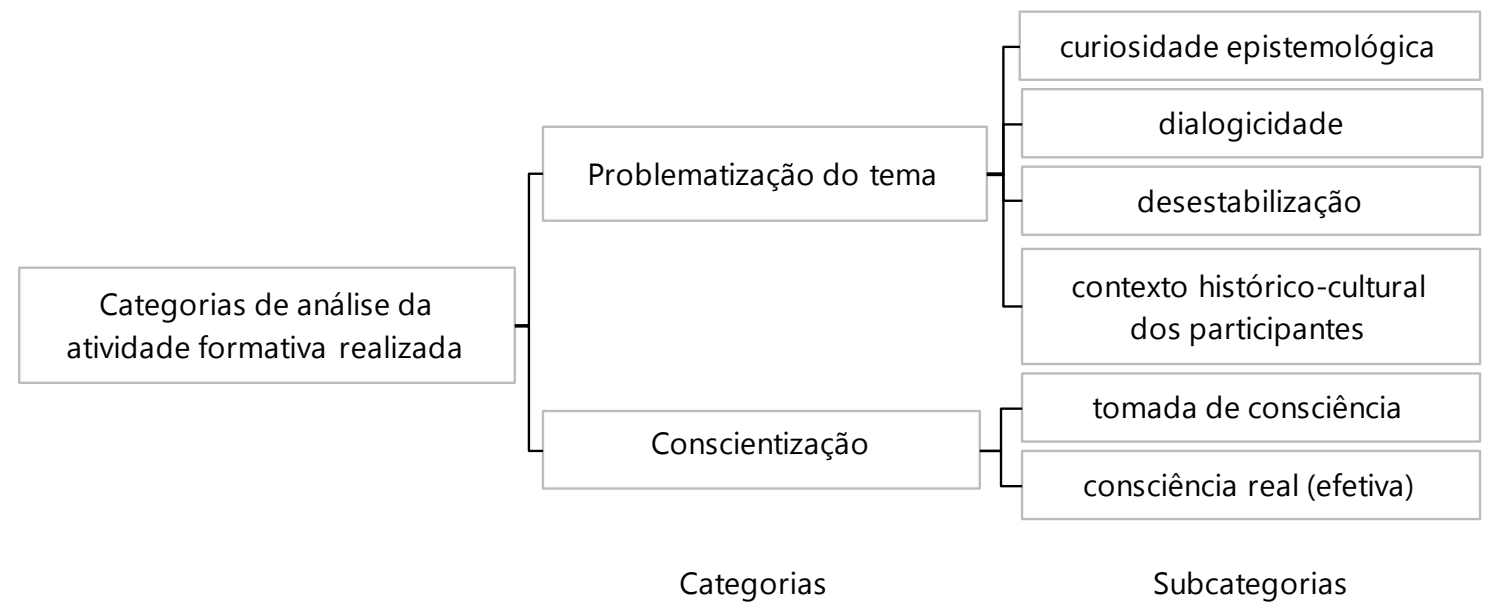

Figura 2. Categorias identificadas no diálogo entre participantes e moderadora durante a atividade formativa.

A problematização, quando efetuada em uma perspectiva freireana, ultrapassa a abordagem de apenas perguntar. Tais questionamentos devem, necessariamente, 
emergir de um problema, de uma contradição (Gehlen, Maldaner, \& Delizoicov, 2012); precisam retratar a realidade na qual os sujeitos estão inseridos. E embora a temática "uso de agrotóxicos nas atividades agrícolas" não tenha sido uma escolha do grupo de participantes da atividade formativa - mas uma opção de nossa pesquisa, confirmou-se nos primeiros diálogos com os participantes da atividade que tal tema se inseria em sua realidade:

P-4: Aconteceu um caso desse aqui. Aqui em Y [nome do município em que reside].

Moderadora: Ah, é? Pouco tempo ou já faz tempo?

P-4: Ah, tem uns... Deve estar fazendo uns três anos, dois anos e pouco.

P-4: Foi até um pai de um aluno daqui, né? Matou o canavial dele tudo.

As falas do professor P-4, citadas acima, ocorreram após a leitura do primeiro texto-base, que trazia informações sobre o acidente por contaminação de agrotóxicos em Lucas do Rio Verde/MT. Nota-se que o professor associa o caso ocorrido naquele município da região médio-norte do estado com outro, registrado em seu município que se localiza na região sudeste de Mato Grosso. Pela continuação do diálogo, observa-se que a utilização desse texto parece ter atingido os objetivos da etapa de problematização inicial, descritas por Delizoicov, Angotti e Pernambuco (2002), uma vez que despertou o interesse dos professores para o assunto:

P-3: Esse texto aqui é dessa revista Ciência, Saúde e Sociedade? De onde é? Ou é referência para escrita desse texto? Esse texto é da onde?

Moderadora: Isso. Esses textos são destas duas referências aí citadas. [...].

P-3: Ele tem uma visão, assim, poética. [...] Mas, assim, talvez é isso que nós vamos conversar aqui, que eu tenho uma curiosidade de ver o outro lado, uma outra vertente disso. Que, às vezes, só vê a agricultura como os vilões e pelo menos aqui nesse trecho mostra muito isso. Então, antes de fazer, por exemplo, uma aplicação provavelmente vai ter um profissional responsável por essa aplicação. [...]. Talvez eu..., eu queria ter mais informação, porque quando a gente vê sobre isso, já li outros textos que realmente coloca essa situação [dos agricultores] como os grandes vilões do uso de pulverização aérea. Mas aí eu vi aqui que é da ANVISA né..., então, eu pergunto: será que isso é um caso [isolado] ou isso é uma constante?

Delizoicov (2005) ressalta que a problematização inicial, além de objetivar a apreensão dos conhecimentos prévios dos educandos (em nosso caso, o grupo participante), pretende despertar as curiosidades deles sobre a temática em estudo. Pelos fragmentos acima, nota-se que o ambiente do desenvolvimento da atividade formativa tornou-se propício às discussões, visto o interesse do grupo de professores, aqui exemplificado pelas falas do professor P-3.

Corroborando Solino e Gehlen (2015), indicamos que a problematização em 
torno do contexto histórico-cultural dos sujeitos favorece a atribuição de novos sentidos e significados sobre o tema de estudo do grupo. Essa constatação deve-se ao relato do professor P-5 ao fim do último encontro da atividade formativa:

P-5: Vendo esses dias que trabalhamos e desde há algum tempo que venho pensando na conscientização e em trabalhar mais sobre isso... Eu me lembro que quando eu terminei o curso de técnico agrícola aqui, fui fazer o estágio em uma fazenda e lá havia uma plantação de uva - além de outras plantações como milho e soja... E nessa plantação de uva tinha um parreiral lá..., à tarde tinha muito mosquito pernilongo e não passou pela minha cabeça que aquele produto que eu estava batendo nas plantas, [era um] um inseticida... O que eu fiz? Eu peguei e pulverizei em mim. [...] É sério, gente. Conhecimento eu tinha, de que era prejudicial. Mas, assim, a curto prazo eu não pensava nos efeitos. Eu sabia de efeitos a longo prazo. E hoje, pensando nessas questões de meio ambiente. [...]. É preciso pensar mesmo mais a fundo com os alunos. Pois realmente essa conscientização do uso correto e da forma correta também é proteção para quem manipula os produtos.

As falas acima do professor P-5 denotam que houve resultados positivos quanto à problematização do tema "agrotóxicos" com o grupo de professores. De algum modo, o sujeito recordou as ações tomadas em momentos anteriores de sua vida, refletiu sobre elas a partir de novos conhecimentos adquiridos e se propõe a uma nova postura e olhar mais cauteloso quanto ao uso de agrotóxicos nas atividades agrícolas. Essa mudança é sinalizada pela sua preocupação em levar a discussão para seus alunos, alterando, desse modo, o ensino para formação de técnicos agrícolas.

No decorrer da atividade formativa, a abordagem da temática agrotóxicos por meio da problematização foi um processo constante. Com o objetivo de ampliar as concepções dos professores sobre o uso desses produtos químicos nas atividades agrícolas, buscou-se que os mesmos analisassem tal situação para além da dimensão técnica, vislumbrando o PP. Assim, o processo dialógico entre moderadora e participantes foi se desenvolvendo de maneira que a primeira estimulava os professores à reflexão a partir de questionamentos que consideravam as dimensões política, econômica, socioambiental e da natureza da ciência, conforme fragmentos abaixo:

Moderadora: E, pensando então nessas situações e nessas tabelas aqui expostas, vocês confiam plenamente nelas?

\section{\{Silêncio\}}

Moderadora: É possível confiar nesses dados?

P-2: É que é uma situação tão complexa que a gente nem tem o que dizer.

\section{P-4: Mas eu creio que sim.}

P-3: Olha, eu acredito, né? Mas não é porque ela seja da classe IV que significa que não vai ser muito tóxico. Então, assim... Lá fala que é pouco perigoso. Mas é perigoso. Não deixa de ser perigoso, né? 
P-1: Isso.... Não deixa de ser perigoso.

P-3: Então eu acho que é mais ou menos isso. Realmente algumas podem acontecer mais do que outras, mas eu acho que todos têm o seu perigo. Não é porque é [classificado] altamente perigoso, muito perigoso, perigoso e pouco perigoso. Mas desse modo nenhum deixou de ser perigoso.

Moderadora: Bom, e foi feito por uma instituição, não é?

P-4: É. Ninguém colocou esses valores "Ah, é tóxico, ah não é”, colocando só por colocar, né?

P-3: É!! Isso aí.

A dialogicidade, mola propulsora da problematização fundamentada em Freire (2000, 2005), desencadeia debates, fertiliza reflexões e instiga questionamentos. A postura adotada pela moderadora, ao se colocar em igualdade epistemológica com os participantes da atividade (tornando todos sujeitos curiosos que querem conhecer), representa o diálogo horizontal de $A$ com $B$. Também a postura dos professores ao expressarem questionamentos e reflexões, como as supracitadas, corrobora o pensamento freireano sobre educação dialógica:

Estimular a pergunta, a reflexão crítica sobre a própria pergunta, o que se pretende com esta ou com aquela pergunta em lugar da passividade em face das explicações discursivas do professor, espécies de respostas a perguntas que não foram feitas. [...]. A dialogicidade não nega a validade de momentos explicativos, narrativos em que o professor e alunos saibam que a postura deles, do professor e dos alunos, é dialógica, aberta, curiosa, indagadora e não apassivada, enquanto fala ou enquanto ouve. O que importa é que professor e alunos se assumam epistemologicamente curiosos (Freire, 2000 , p. 86 , grifo do autor).

O clímax da problematização ocorreu no segundo encontro da atividade, naquilo que se configurou como o encerramento da problematização inicial, uma vez que, em nosso planejamento da atividade, se tratava do momento em que os professores sentiriam necessidade de novos conhecimentos para responder ao problema proposto. Apresentamos trechos desse diálogo, aqui iniciado pela questão principal da problematização proposta:

Moderadora: [...] E pensando nesses milhões de toneladas de agrotóxicos e que somos o maior consumidor mundial de agrotóxicos, onde é que está indo parar esses milhões de agrotóxicos?

\section{\{Silêncio\}}

P-2: Uma parte no solo e outra na barriga do povo.

$\{$ Todos riem $\}$ 
P-1: [...] De manhã nós comentamos do leite materno, né? Que foi detectado maciçamente nas mães do município de Lucas do Rio Verde. Quase todas estavam com resquícios de resíduos de agrotóxicos.

Moderadora: É, pra algum lugar está indo [os agrotóxicos], pois a gente aprende que na natureza tudo é um ciclo. Temos o ciclo da água, do carbono.... As substâncias químicas elas mudam de locais, mas não tem como desaparecer... Elas podem até se decompor, se transformar em outras... Existe uma série de processos envolvidos nisso. Alguém quer comentar sobre?

\section{\{Silêncio\}}

Nota-se, pelos silêncios registrados em alguns momentos e na descontração de outros, que os participantes não conseguiram responder ao questionamento a partir dos conhecimentos que já possuíam. Delizoicov (1983, p. 86) destaca que esta é uma das funções da problematização: desestabilizar o conhecimento anterior do sujeito, "criando uma lacuna que o faz sentir falta daquilo que ele não sabe".

A partir desse momento, iniciou-se a etapa de Organização do Conhecimento com a explicação sobre classes e indicadores toxicológicos e de periculosidade ambiental. Esses conteúdos não foram retratados apenas em seus conceitos científicos. O processo de problematização foi retomado quando se vislumbrou tais conteúdos a partir do Princípio da Precaução (aspectos de incertezas científicas sobre os impactos de ingredientes ativos específicos). Entretanto, como evidenciado nos diversos silêncios registrados durante a atividade, observa-se que o processo de desestabilização do conhecimento dos professores perdurou para além do fim da problematização inicial.

Foi notado, pela moderadora, que houve a redução da interação do grupo para responder aos questionamentos ou para sustentar seus argumentos após a indagação sobre o destino final dos agrotóxicos aplicados nas lavouras. Os próprios professores acabaram por confidenciar suas angústias quanto à lacuna que eles perceberam ter para responder à questão principal da problematização.

P-3: Quando a gente começou a falar sobre esses princípios.... Você vê, assim, que eu acho que até a nossa participação agora ela tem sido bem limitada. Porque, para mim mesmo, tem muita coisa que eu nunca parei pra pensar e avaliar. É como o P-2 colocou, a gente se preocupa muito com a planta. O que vai acontecer com a planta, mas...

P-1: O que vai provocar além...

P-3: Isso. Se vai causar algo às pessoas, até mesmo no meio ambiente. Acho que eu não tinha pensado nisso até agora.

P-2: É como você estava dizendo antes. A gente trabalha com ensino técnico, se preocupa com a parte técnica: o que se usa, o que se pode usar.... Eu não paro, assim, pra pensar, por exemplo, no que o glifosato causa no meio ambiente ou para o ser humano. Porque é muito técnico. [...] 
Assim ficou sinalizado, mais uma vez, o êxito da problematização realizada ao promover tal desestabilização e desvelar a situação-limite sobre o uso de agrotóxicos aos professores. Os professores P-2 e P-3 perceberam que seu modo de olhar para a situação do uso de agrotóxicos nas atividades agrícolas centrava-se, basicamente, nos aspectos técnicos de produção (quantidade e forma de aplicação de agrotóxicos, produtividade, efeitos nas plantas cultivadas). Pouca atenção era dispendida à compreensão dos efeitos de tais produtos sobre o ambiente, saúde humana e demais organismos vivos. Porém, a tomada de consciência sobre as posturas que manifestavam anteriormente, pode demonstrar indícios de que os professores consideraram aspectos socioambientais para pensar nos impactos provenientes das atividades antrópicas.

Sobre esse processo de tomada de consciência, Freire (1979) destaca que ela ainda não é conscientização, pois esta consiste no desenvolvimento crítico da tomada de consciência. A conscientização ultrapassa a mera apreensão do fato, e colocase criticamente, "num sistema de relações, dentro da totalidade em que se deu, [...], superando-se a si mesma, aprofundando-se" (Freire, 1983, p. 77). Desse modo, a tomada de consciência pode ocorrer tanto dentro de um nível de consciência - de maneira a despertar, aos poucos, a criticidade no sujeito - quanto na passagem de um nível para outro - neste caso, da consciência real (efetiva) para a consciência máxima possível (Freire, 2005). Fundamentado nos trabalhos de Lucien Goldmann, Freire (2005, p. 126) caracteriza a consciência real como sendo aquela em que os "sujeitos encontramse limitados na possiblidade de perceber mais além das 'situações-limites' [...]”. Isto é, não conseguem vislumbrar além dos obstáculos impostos pela realidade, adquirindo uma postura conformista de aceitar a realidade sem questionamentos. Sem a adoção de uma consciência crítica torna-se impossível encontrar alternativas para a superação das situações-limites, ou seja, vislumbrar o inédito-viável e, assim, alcançar uma consciência máxima possível.

Lindemann (2010), ao avaliar a percepção de agricultores sobre os agrotóxicos, apontou como características da consciência real (efetiva): a "compreensão limitada sobre contaminação/intoxicação; [...] incapacidade de questionar a situação de vida no campo (muitas vezes representada pelo conformismo); [...] desenvolvimento de culturas balizadas pelo uso indiscriminado de insumos externos" (p.262). Nas falas dos professores participantes de nossa atividade formativa observou-se posturas semelhantes, que nos permitiram classifica-las como constituintes da consciência real (efetiva) manifestada por eles. A exemplo, temos o diálogo entre moderadora e participantes sobre os números da comercialização de agrotóxicos em cada estado brasileiro:

\section{P-2: E agora vamos analisar.... Por que São Paulo está em primeiro lugar na comercialização de agrotóxicos?}

Moderadora: Por quê?

P-3: Bom, São Paulo está entre os maiores produtores de fruta, não é? Laranja, citrus, então... Talvez seja isso... 
P-2: Tá vendo? A soja acaba não sendo a grande vilã. Porque o nosso consumo maior é de frutas e verduras e eles estão utilizando lá também.

Moderadora: Mas essa questão do "nós não consumismo soja"... E toda esses produtos industrializados que usam a soja e o milho como matéria prima? O óleo de soja...

P-4 e P-1: Tem vários mesmo.

P-2: Mas veja... Compara o tamanho do estado de Mato Grosso e de São Paulo. Acho que temos uma extensão três vezes maior. E olha a diferença de valores de comercialização.

As falas acima do professor P-2 sinalizam a negação da existência de problemas no estado de Mato Grosso referente ao uso de agrotóxicos na cultura da soja. Primeiro, o professor tenta argumentar que os riscos de intoxicação humana por agrotóxicos são maiores pelo consumo de frutas e verduras e, uma vez que não consumimos soja in natura, não é necessária tanta preocupação com o consumo de agrotóxicos nessa cultura. Com as réplicas da moderadora e demais participantes nas falas seguintes, o professor em questão procura apoio na comparação das extensões geográficas dos estados brasileiros. Torna-se aparente que os argumentos utilizados pelo professor P-2 denotam uma análise ingênua e acrítica da realidade, demonstrando que o mesmo ainda não alcançou a consciência máxima possível.

Noutro diálogo entre P-2 e P4 observa-se uma postura fatalista (Freire, 2005) de não enxergar possibilidades de produção agrícola sem o uso de agrotóxicos. Tais sujeitos demonstram alinhamento com a racionalidade econômica ao afirmarem que o banimento de determinados tipos de agrotóxicos pode encarecer o preço para a produção agrícola e, consequentemente, tal aumento ser repassado aos consumidores:

P-2: Mas agora eu vou falar... Tem muito desses produtos, não sei se vocês concordam.... Se for proibido de uma vez e não tiver nenhum substituto...

\section{P-4: Prejuízo né?}

P-2: A carne que ele paga vinte reais hoje em dia, ele vai pagar cinquenta ou sessenta e a gente tem que pensar nos impactos. Como ter carne de qualidade e em preço acessível? E muitos desses produtos, se sair do sistema de produção, o preço do produto de consumo vai aumentar...

Fica, assim, sinalizado que os professores participantes da atividade formativa se encontram no nível de consciência real (efetiva) sendo necessária uma compreensão mais ampliada da realidade a partir de uma reflexão crítica.

Ao esclarecer as dimensões obscuras resultantes de sua aproximação com o mundo, os sujeitos emergem no processo de conscientização (Freire, 1979), ou seja, possivelmente transitarão do nível de consciência real para a consciência máxima possível. No entanto, conforme já mencionado, a tomada de consciência - elemento essencial da conscientização - pode ocorrer dentro de um mesmo nível, de maneira que cada 
descoberta que revele um pouco mais a realidade, eleva o pensamento crítico do sujeito. Foram observadas algumas falas dos professores que demonstram tal processo. Por exemplo, pelos fragmentos abaixo, o professor P-2 reconhece a influência das questões políticas e econômicas sobre a regulamentação de agrotóxicos no Brasil, de maneira a enxergar a situação-limite; no entanto, ele não consegue superar tal obstáculo.

Moderadora: Será que esse princípio [da precaução] é considerado, atualmente, na tomada de decisão para as políticas públicas? Para o uso de agrotóxicos? Será que o governo pensa nesses graus de ameaças ou no tipo de medidas que podem ser tomadas?

P-2: Eu acho que é mais uma questão econômica, né? Acho que se a ANVISA, o Ministério do Meio Ambiente ou as instituições que fazem o teste comprovar que não tem o dano ambiental ou pra saúde... Então vai muito da questão econômica. Defensivo é muito usado, o agricultor precisa...É importante para a agricultura? Se é, mesmo que tenha a incerteza, vai sendo usado até que se prove o contrário.

Moderadora: Então será que há influências de questões um tanto políticas como econômicas quando a gente pensa nessa.... Tanto na promoção como no banimento, talvez, né?

P-2: Acho que tem muita questão política e econômica... e questão de segurança... é questão mesmo de estratégia do país. Questão, por exemplo, tem um monte de incertezas que é provável de se propor, embora nada se tenha provado, há essas incertezas... Comunidade científica, principalmente na área da saúde tenta provar... Mas se a gente considerar o princípio da precaução, que medidas se vai tomar? Vai suspender até que.... Não pode suspender, porque se suspender, vai ter um monte de gente lá embaixo - na cadeia que vai ser prejudicado, os produtores... E se o produtor for mal, o país também vai mal e a produção de alimentos como fica? Vai deixar de produzir, vai aumentar o custo de produção? Tem um monte de questão social também.

A fala do professor P-2 até transparece que o mesmo vislumbrou o inédito-viável quando ele associa a tomada de decisão sobre o banimento de um agrotóxico ao PP. Compartilhamos as ideias de Lindemann (2010) de que o inédito-viável para a superação de situações-limites relacionadas ao elevado consumo de agrotóxicos está na busca por formas menos agressivas de produção ao meio ambiente e saúde humana. E, as práticas agroecológicas parecem ser o caminho que temos disponível para isso, mas que não foram cogitadas pelos participantes da atividade formativa realizada.

Sendo assim, não foi possível diagnosticar o nível de consciência máxima possível nesses sujeitos, uma vez que ela engloba aspectos como: a capacidade de problematizar a realidade pela complexidade das inter-relações socioambientais (que incluem as dimensões ambiental, ética, cultural, política e econômica); a preocupação com a integridade do ambiente e dos organismos que nele se inserem - inclusive os seres humanos; e a busca por práticas agrícolas que dependam minimamente de insumos externos para sua produção, a exemplo, o abandono gradativo do uso de agrotóxicos. Embora tal nível de consciência crítica não tenha sido alcançado no desenvolvimento da atividade formativa, convém destacar que a problematização realizada teve êxito para 
despertar a tomada de consciência dos professores formadores de técnicos agrícolas. Destacamos, por exemplo, os fragmentos de falas que indicam o momento em que o professor P-4 percebe que, no decorrer do tempo, o acúmulo de ingredientes ativos provenientes dos agrotóxicos representam um perigo ao ambiente e saúde humana:

P-4: Tem tudo a ver isso mesmo. Dependendo da quantidade que você usa... Tipo, todo ano você vai usando, vai usando [agrotóxicos]... Igual fala aí [nos gráficos], cinquenta por cento é grave [ao ambiente e saúde] e o outro restante?

\section{\{Silêncio\}}

P-4: É aquela pergunta que a senhora deixou ontem aí... Pra onde é que vai? Se tiver um técnico, dez anos, só ele mexendo na fazenda, entendeu?

P-2: Vai acumulando.

\section{P-4: Vai acumulando. Agora pensa, pra onde é que tá indo?}

Nos fragmentos acima, observa-se, ainda, que o silêncio manifestado pelos demais participantes representa a desestabilização destes para encontrar respostas ao questionamento feito por P-4 e que a participação do professor P-2 no diálogo pode ter representado o início de sua tomada de consciência. O professor P-4 foi o que demonstrou explicitamente o maior número de reflexões sobre o tema discutido em grupo, de maneira a tornar possível o diagnóstico sobre sua tomada de consciência. Entretanto também houve momentos em que outros participantes sinalizaram a tomada de consciência, conforme se observa pelos fragmentos que se seguem:

Moderadora: Isso que ia perguntar para vocês. O que vocês consideram? Vamos pegar este exemplo do [caso do] glifosato... em qual destas situações vocês acreditam que se encontra? Risco, incerteza ou ignorância?

\section{P-2: Eu concordo que seja risco.}

P-4: Mas, e aquela porcentagem [de agrotóxicos aplicados] que a gente não sabe para onde vai?

P-5: Pois é...

P-2: Professora, eu mantenho meu posicionamento de que essa questão é [uma situação] de risco. Porque um estudo para contestar a FAO e EPA tem que ser um estudo muito bom! Não é qualquer pessoa ou instituição que contesta. Porque se a FAO e a EPA estão dizendo que não [há perigos iminentes], eu acredito. E pode ter o dia que estas instituições de confiança vão concluir que há outros perigos graves também.

Moderadora: [...]. Será que a partir desses estudos controversos sobre os efeitos negativos [ao ambiente e saúde] do uso de agrotóxicos, há incertezas nesses impactos do glifosato? Ou será que podemos confiar no que está posto? Tipo: "não, se está falando que não tem perigo, a gente continua utilizando". 


\section{P-5: Pelo que fala aí. Não sei.... Está dizendo que não corre risco, mas daqui mais dez anos vai haver um acúmulo maior também dos resíduos [desses produtos].}

\section{P-4: Lógico!}

Destaca-se, no diálogo acima, o posicionamento do professor P-2 de considerar que os ingredientes ativos dos agrotóxicos devem ser encarados como uma situação de risco e a dúvida levantada pelo professor P-4 para contra-argumentar tal posicionamento.

Somos conscientes de que a realização desta atividade formativa, de pequena carga horária e promovida em um curto espaço de tempo, não foi capaz de propiciar uma tomada de consciência dos professores para a alteração de seu nível (real/efetiva para máxima possível). Entretanto, conforme descrito nesta seção, há indícios de que houve a apreensão de novos conhecimentos e a ampliação da visão de mundo dos sujeitos.

\section{Considerações finais}

A realização de uma atividade dialógica sobre o uso de agrotóxicos, desenvolvida com um grupo de professores formadores de técnicos agrícolas, contribuiu para a problematização e conscientização a respeito do problema. Percebemos que ocorreu a desestabilização do conhecimento dos professores ao não conseguirem responder de imediato à questão problematizadora sobre o destino final dos agrotóxicos aplicados nas lavouras. Ficou evidenciada a apreensão de novos conhecimentos pelos professores quando eles expressaram considerar a integridade física do ambiente e dos seres vivos no que diz respeito ao uso de agrotóxicos nas atividades agrícolas. Além disso, devido às discussões estabelecidas sobre as inter-relações das dimensões ambiental, social e econômica, e destas com a natureza da ciência, observou-se a ampliação da visão de mundo dos participantes da atividade.

A realização de atividades formativas com maior carga horária e em espaço de tempo mais longo pode melhor proporcionar uma eventual tomada de consciência de professores em formação com alteração de seu nível (real/efetiva para máxima possível). Contudo, em nossa pesquisa de natureza formativa, isso não foi impeditivo para observarmos a alteração da percepção do grupo participante da atividade - de um olhar totalmente técnico sobre o uso de agrotóxicos para uma preocupação com as possíveis ameaças ao ambiente e seres vivos provenientes da aplicação desses produtos químicos. Algo que, por si só, já demonstra um avanço significativo.

Em relação à inserção do PP no ensino de ciências por meio de discussões sociocientíficas, ressalta-se que pesquisadores da área educacional têm associado tal princípio à alfabetização científica (Praia, Gil-Pérez, \& Vilches, 2007; Simonneaux, 2001; Levinson, Kent, Pratt, Kapadia, \& Yogui, 2012; Martínez Pérez, \& Lozano, 2013), sem, no entanto, detalhar sobre tal aplicação - talvez por compreender que este princípio seja algo intrínseco da própria educação científica. Kolsto (2006), por exemplo, ao relatar um estudo qualitativo sobre os argumentos de estudantes da educação básica noruegueses para a tomada de decisão de uma questão sociocientífica hipotética (local de construção 
de novas linhas de energia e o possível aumento do risco de leucemia infantil), encontrou, na análise dos resultados, o PP como um dos modelos argumentativos utilizados pelos alunos.

Infelizmente, na educação brasileira, o PP parece ainda não ser tão conhecido, difundido e/ou discutido - conforme resultados de nossas análises em periódicos da área (Souza, Marques, \& Machado, 2016) e das entrevistas realizadas com professores (catarinenses e mato-grossenses) formadores de técnicos agrícolas (Souza, 2016) ${ }^{4}$. Desse modo, destaca-se que o PP pode ser discutido em questões sociocientíficas no ensino de ciências, tanto pela apresentação conceitual de suas formulações, e, principalmente, a partir da compreensão e discussão de seus elementos constituintes e pressupostos - como as incertezas científicas, possibilidade de ameaças das atividades antrópicas e necessidade da tomada de decisão participativa -, bem como nas articulações desses com o enfoque CTS. Acreditamos no potencial do PP em discussões sociocientíficas para o alcance de uma educação que desvele a realidade e promova a formação da consciência crítica e a autonomia dos sujeitos para a tomada de decisão, portanto, uma educação emancipatória (Freire, 2000).

A problematização por meio do PP não contempla apenas a discussão de suas diversas formulações, mas o contexto histórico-cultural em que ele é invocado. $\mathrm{Na}$ contemporaneidade atual, tal contexto se relaciona à sociedade (industrial) de risco (Beck, 2011) e seus diversos setores produtivos, como o agronegócio. Desse modo, elementos constituintes desse princípio, como o posicionamento precaucionário de duvidar daquilo que ainda não está plenamente estabelecido cientificamente (incertezas científicas) e o entendimento de que a tomada de decisão exige um processo aberto, participativo e democrático (SEHN, 1998; COMEST, 2005), o tornam capaz de promover espaços para diálogos sobre a natureza da ciência e estudos das interações CTS.

Por fim, a exitosa experiência aqui relatada (na promoção de discussões sociocientíficas por meio da inserção do PP) teve no grupo de professores do ensino técnico um elemento singular e importante. Outras investigações contemplando públicos similares ou de outros níveis educacionais, como da educação básica e ensino superior - por exemplo, na formação de professores ou mesmo com estudantes, podem contribuir na consolidação dos resultados aqui alcançados. Do mesmo modo, investigações envolvendo o PP em outras temáticas, podem trazer novas reflexões e possibilitar a avaliação desse princípio problematizador e promotor da conscientização sociocientífica e ambiental.

4 Os resultados da análise das entrevistas com professores (catarinenses e mato-grossenses) formadores de técnicos agrícolas podem ser encontrados na seção 5.3.1 da tese referenciada. 


\section{Agradecimentos}

À CAPES, pela concessão de bolsa no Programa de Doutorado Sanduíche no Exterior (Processo no 99999.002910/2014-04). Ao Fundo de Apoio à Manutenção e ao Desenvolvimento da Educação Superior de Santa Catarina (FUMDES/SC) pelo apoio e financiamento desta investigação a partir da concessão de bolsa de estudos em nível de doutorado. Aos seis professores participantes da atividade formativa elaborada nesta pesquisa por permitirem que tal momento de formação continuada fosse utilizado como objeto de investigação.

\section{Referências}

ABRASCO (Associação Brasileira de Saúde Coletiva). (2010). Moção contra o uso dos agrotóxicos e pela vida. I Simpósio Brasileiro de Saúde Ambiental. Belém do Pará, 10 dez. 2010.

ABRASCO (Associação Brasileira de Saúde Coletiva). (2015). Dossiê ABRASCO: um alerta sobre os impactos dos agrotóxicos na saúde. Rio de Janeiro: EPSJV; São Paulo: Expressão Popular.

Auler, D., \& Delizoicov, D. (2006). Ciência-Tecnologia-Sociedade: relações estabelecidas por professores de ciências. Revista Electrónica de Enseñanza de las Ciencias, 5(2), 337355.

Auler, D. (2011). Novos Caminhos para a Educação CTS: ampliando a participação. In W. L. P. dos Santos, \& D. Auler (Org.), CTS e Educação Científica: desafios, tendências e resultados de pesquisa (pp. 7398). Brasília: Editora UnB.

Belo, M. S. S. P., Pignati, W., Dores, E. F. G. C., Moreira, J. C., \& Peres, F. (2012). Uso de agrotóxicos na produção de soja do estado do Mato Grosso: um estudo preliminar de riscos ocupacionais e ambientais. Revista Brasileira de Saúde Ocupacional, 37(125), $78-88$.

Beck, U. (2011). Sociedade de risco: rumo a uma outra modernidade. 2. ed. São Paulo: Editora 34.

Céleres. (2015). Informativo Biotecnologia. Uberlândia, MG: Céleres.

COMEST (Commission on the Ethics of Scientific Knowledge and Technology). (2005). The precautionary principle. Paris: UNESCO.

Comissão das Comunidades Europeias. (2001). Livro branco: estratégia para uma futura política em matéria de químicos. Bruxelas: Comissão das Comunidades Europeias.

Decreto $n .^{\circ} 4.074$, de 4 de janeiro de 2002 (2002). Regulamenta a Lei no 7.802, de 11 de julho de 1989, que dispõe sobre a pesquisa, a experimentação, [...] e dá outras providências. Brasília. 
Delizoicov, D. (1983). Ensino de Física e a concepção freireana da educação. Revista Brasileira de Ensino de Física, 5(2), 85-98, 1983.

Delizoicov, D. (2005). Problemas e problematizações. In: Pietrocola, M. (Org.). Ensino de física: conteúdo, metodologia e epistemologia numa concepção integradora (pp. 125150). 2. ed. Florianópolis: UFSC.

Delizoicov, D., \& Auler, D. Ciência, tecnologia e formação social do espaço: questões sobre a não-neutralidade. Alexandria, 4(2), 247-273.

Delizoicov. D., Angotti, J. A., \& Pernambuco, M. M. (2002). Ensino de ciências: fundamentos e métodos. São Paulo: Cortez.

Fensham, P. J. (2014). Scepticism and trust: two counterpoint essentials in science education for complex socio-scientific issues. Cultural Studies of Science Education, 9(3), 649-661.

Freire, P. (2000). Pedagogia da autonomia: saberes necessários à prática educativa. 15. ed. São Paulo: Paz e Terra.

Freire, P. (1979). Conscientização: teoria e prática da libertação. São Paulo: Cortez \& Moraes.

Freire, P. (1983). Extensão ou comunicação?. 7. ed. Rio de Janeiro: Paz e Terra.

Freire, P. (2005). Pedagogia do oprimido. 47. ed. São Paulo: Paz e Terra.

Gehlen, S. T., Maldaner, O. A., \& Delizoicov, D. Momentos pedagógicos e as etapas da situação de estudo: complementaridades e contribuições para a educação em ciências. Ciência \& Educação, 18(1), 1-22.

Gehlen, S. T., Auth, M. A., Auler, D., Maldaaner, O. A., \& Pansera-de-Araújo, M. C. (2008). Freire e Vigotski no contexto da Educação em Ciências: aproximações e distanciamentos. Ensaio: Pesquisa em Educação em Ciências, 10(2), 267-282.

Gonçalves, F. P., \& Marques, C. A (2012). A circulação inter e intracoletiva de conhecimento acerca das atividades experimentais no desenvolvimento profissional e na docência de formadores de professores de química. Investigações em Ensino de Ciências, 17(2), 467-488.

Guyton, K. Z., Loomis, D., Grosse, Y., Ghiassassi, F. E., Benbrahim-Tallaa, L., Guha, N., ..., \& Straif, K (2015). Carcinogenicity of tetrachlorvinphos, parathion, malathion, diazinon, and glyphosate. The Lancet Oncology, 16(5), 490-491.

IBAMA.(2015).Planilha:Histórico de comercialização(2000-2014). Recuperadode http:// www.ibama.gov.br/phocadownload/Qualidade_Ambiental/historico_2000_2014.xls

Kosto, S. D. (2006). Patterns in Students' Argumentation Confronted with a Risk-focused Socio-scientific Issue, International Journal of Science Education, 28(14), 1689-1716. 
Lacey, H. (2007). Há alternativas ao uso dos transgênicos?Novos estudos - CEBRAP, 78, 31-39.

Lacey, H. (2006). O princípio de precaução e a autonomia da ciência. Scientiae studia, $4(3), 373-392$.

Levinson, R., Kent, P., Pratt, D., Kapadia, R., \& YoguiI, C. (2012). Risk-based decision making in a scientific issue: a study of teachers discussing a dilemma through a microworld. Science Education, 96(2), 212-233.

Lieber, R. R (2008). O princípio da precaução e a saúde no trabalho. Saúde e Sociedade, $17(4), 124-134$.

Lindemann, R. H. (2010). Ensino de química em escolas do campo com proposta agroecológica: contribuições a partir da perspectiva freireana de educação. (Tese de Doutorado). Programa de Pós-Graduação em Educação Científica e Tecnológica, Universidade Federal de Santa Catarina, Florianópolis.

Lopes, G. V., \& Dunda, F. F. E. (2015). O risco da contaminação global: o combate à epidemia de Ebola na África como vetor de cooperação internacional. Revista Eletrônica de Comunicação, Informação \& Inovação em Saúde, 9(1).

Magalhães, A. (2007). Especial Paulo Freire 3: reconhecido no mundo, pouco aplicado no Brasil. Recuperado de http://www.camara.gov.br/internet/radiocamara/ default. asp? selecao $=$ MAT\&Materia $=50034$

Martínez Pérez, L. F., \& Lozano, D. L. P. (2013). Discurso Ético y Ambiental sobre Cuestiones Sociocientíficas: aportes para la formación del profesorado. Bogotá/Colômbia: Universidad Pedagógica Nacional.

Miranda, A. C., Moreira, J. C., Carvalho, R. de, \& Peres, F. (2007). Neoliberalismo, uso de agrotóxicos e a crise da soberania alimentar no Brasil. Ciência \& Saúde Coletiva, 12(1), 7-14.

Moraes, R., \& Galiazzi, M. C. (2006). Análise textual discursiva: processo reconstrutivo de múltiplas faces. Ciência \& Educação, 12(1), 117-128.

NPIC (National Pesticide Information Center). (2014). Glyphosate. Oregon: National Pesticide Information Center.

Oliveira, A. M., \& Recena, M. C. P. (2009). A investigação temática e a análise textual discursiva: busca por temas geradores. In Atas do VII Encontro Nacional de Pesquisa em Educação em Ciências. Florianópolis, SC: ABRAPEC.

ONU (Organização das Nações Unidas). (1992). Declaração sobre meio ambiente e desenvolvimento. Conferência das Nações Unidas sobre Meio Ambiente e Desenvolvimento. 03-14 jun. 1992.

Praia, J., Gil-Pérez, D., \& Vilches, A. (2007). O papel da natureza da ciência na educação para a cidadania. Ciência \& Educação, 1(2), 141-156. 
Prestes, R. F., Lima, V. M. R, \& Ramos, M. G. (2011). Contribuições do uso de estratégias para a leitura de textos informativos em aulas de Ciências. Revista electrónica de enseñanza de las ciencias, 10(2), 346-367.

Rigotto, R. M. (2011). O uso seguro de agrotóxicos é possível? In F. Londres (Org.). Agrotóxicos no Brasil: um guia para ação em defesa da vida (pp. 48-51). Rio de Janeiro: AS-PTA - Assessoria e Serviços a Projetos em Agricultura Alternativa.

Sandin, P. (1999). Dimensions of the precautionary principle. Human and Ecological Risk Assessment, 5(5), 889-907.

Santos, W. L. P., \& Schnetzler, R. P. (2010). Educação em Química: compromisso com a cidadania. 3. ed. Ijuí: Unijuí.

SEHN (Science \& Environmental Health Network). (1998). Wingspread Statement on the Precautionary Principle. Wisconsin: Wingspread Conference Center.

Simonneaux, L (2001). Role-play or debate to promote students' argumentation and justification on an issue in animal transgenesis. International Journal of Science Education, 23(9), 903-927.

Solino, A. P., \& Gehlen, S. T. (2015). O papel da problematização freireana em aulas de ciências/física: articulações entre a abordagem temática freireana e o ensino de ciências por investigação. Ciência \& Educação, 2(4), 911-930.

Souza, L. C. A. B. (2016). A problematização do Princípio da Precaução na formação do técnico agrícola: reflexões para o enfrentamento da racionalidade instrumental a partir de uma questão sociocientífica. (Tese de Doutorado em Educação Científica e Tecnológica). Universidade Federal de Santa Catarina, Florianópolis.

Souza, L. C. A. B., Marques, C. A., \& Machado, A. A. S. C (2016). O princípio da precaução no ensino de ciências como possibilidade para a promoção de discussões sociocientíficas. Investigações em Ensino de Ciências, 21(2), 137-152.

Thornton, J. W. (2000). Beyond risk: an ecological paradigm for persistent organic pollutants. International Journal of Occupational and Environmental Medicine, 6(4), 318-330.

Tickner, J. A., \& Raffensperger, C. (1998). The precautionary principle in action: a handbook. Windsor, North Dakota: Science and Environmental Health Network.

Torres, J. R., Gehlen, S. T., Muenchen, C., Gonçalves, F. P., Lindemann, R. H., \& Gonçalves, F. J. F. (2008). Resignificação curricular: contribuições da investigação temática e da análise textual discursiva. Revista Brasileira de Pesquisa em Educação em Ciências, 8(2). 


\section{Leila Cristina Aoyama Barbosa Souza \\ http://orcid.org/0000-0002-6021-3855}

Secretaria de Estado de Ciência e Tecnologia de Mato Grosso Escola Técnica Estadual de Educação Profissional e Tecnológica de Rondonópolis, Brasil aoyama.leila@gmail.com

\section{Carlos Alberto Marques}

(ㄷ) https://orcid.org/0000-0002-4024-7695 Universidade Federal de Santa Catarina Departamento de Metodologia de Ensino Florianópolis, Brasil carlos.marques@ufsc.br

Submetido em 04 de Setembro 2016 Aceito em 03 de Junho 2017 Publicado em 31 de Agosto de 2017 